\title{
Odontometric analysis of molars for sex determination
}

\author{
Larissa Chaves Cardoso Fernandes'1, Carolina Vieira Lucena Veloso², Julyana de Araújo Oliveira², Paloma \\ Rodrigues Genu³, Bianca Marques Santiago², Patrícia Moreira Rabello²
}

${ }^{1}$ Universidade de Pernambuco - UPE, Pernambuco Dental School, Area of Forensic Dentistry, Recife, PE, Brazil

2Universidade Federal da Paraiba - UFPB, School of Dentistry, Department of Clinical and Social Dentistry, Area of Forensic Dentistry, João Pessoa, PB, Brazil

${ }^{3}$ Universidade Federal de Pernambuco - UFPE, School of Dentistry, Department of Social Medicine, Area of Forensic Dentistry, Recife, PE, Brazil

\begin{abstract}
Aim: To investigate the existence of sexual dimorphism between the first and second permanent molars. Methods: A cross-sectional, observational, blind study using comparative and statistical descriptive procedures. The sample included 50 pairs of plaster casts from undergraduate dental students ( 25 men/25 women) from the Federal University of Paraíba, João Pessoa/PB, Brazil, aged 20-26 years. Odontometric measurements of first and second maxillary/mandibular, right/ left permanent molars were performed. Mesiodistal (MD) and buccolingual/palatal (BL/BP) widths and the distance between the lingual cusps of corresponding molars in opposite quadrants, were measured. The data were analyzed by Student's $t$ test and ANOVA with Bonferroni $(p \leq 0.05)$. Results: The crowns of all first molars were statistically larger in men than in women $(p<0.05)$. Maxillary and mandibular left second molars (\#27 and \#37) did not differ in their MD widths ( $p=0.66$, $p=0.75$ ), whereas mandibular left and right second molars (\#37 and \#47) showed statistically different $B L$ widths $(p=0.007$ and $p=0.008)$. As to the distance between the lingual cusps, only the first left-to-right mandibular molars (\#36-46) showed no sex dimorphism ( $p=0.107)$. Conclusions: Molars are larger in males than in females. Individually, first molars demonstrated higher evidence of sex distinction than second molars.
\end{abstract}

Keywords: Forensic Dentistry. Molar. Odontometry. Sex Characteristics.

\section{Introduction}

Forensic dentistry is a branch of the forensic sciences that provides information to support the Court of Justice decisions, especially with regard to human identification and clarification of facts with legal interest $\mathrm{t}^{1,2}$.

Approximately $70 \%$ of the identifications performed worldwide in cases of mass disasters are obtained by forensic dentistry ${ }^{3,4}$. Human identification by the study of teeth has gained considerable importance, mainly in the absence of fingerprint data ${ }^{5}$. Teeth are the most stable, durable and resistant organs of the human body ${ }^{6}$, able to stand up very high temperatures and the process of cadaveric decomposition ${ }^{7,8}$.

Dental features may assist the reconstruction of forensic biological profile of unknown individuals. As such, teeth could serve as important tools for estimating age and height at the death time as well as ethnic group and $\operatorname{sex}^{7,9-12}$. Sex determination is of paramount importance in cases when visual identification of the sex is impossible, thus eliminating about $50 \%$ of possibilities in the examined population ${ }^{8}$. Although some of the dental features may change in lifetime, anatomical peculiarities, and missing, decayed 
and restored teeth do provide specific data for ante-mortem and post-mortem comparisons ${ }^{13}$.

Studies have shown statistically significant differences in the dental patterns of men and women by odontometric measures, that include the mesiodistal and buccolingual distances between the crowns of permanent teeth ${ }^{9,14}$. Among all teeth, molars have greater potential for race differentiation ${ }^{15}$. Herein, odontometric measures were used to evaluate sexual dimorphism in the first and second maxillary/mandibular permanent molars to assist the process of human identification.

\section{Material and methods}

This study is in accordance with the Brazilian Resolution no. 466/12 of the National Health Council, Ministry of Health, which regulates research involving human beings, and had prior approval of the Research Ethics Committee at the Center for Health Sciences, Federal University of Paraíba (CAAE: 30967814.6.0000.5188).

This was a cross-sectional, observational, blind study using comparative, statistical and descriptive procedures. The study approach was based on intensive direct observation of maxillary and mandibular plaster casts. The universe consisted of 191 pairs of maxillary and mandibular plaster casts belonging to students from the Federal University of Paraíba (UFPB), which were part of the Occlusion discipline database in this institution. The casts were thoroughly analyzed and we excluded from the sample those with missing molars; poorly positioned teeth; restorations of free faces that could change dental dimensions; failures in the cast (e.g. bubbles and fractures) or those from individuals with previous history of orthodontic treatment. The final sample consisted of 50 pairs of plaster casts, where 25 were from females and 25 from males, aged 20 to 26 years.

A pilot study including other 40 pairs of plaster casts from the same database was carried out prior to the full study for training the examiner. The time between the first and second analyses was eight days, yielding intraclass correlation coefficient values between 0.868 and 0.999 . These casts were excluded from the final sample.

The measurements were performed with a digital caliper (Stainless-Hardened $^{\circledR}$ - 150 mm, Mauá, São Paulo, Brazil) and consisted in the following variables: mesiodistal width -the greatest distance between the proximal surfaces of the molar tooth (Figure 1); buccolingual/palatal width - the distance between the outermost points of the molar crowns (Figure 2) and the distance between the lingual cusps of the corresponding molar teeth in opposite quadrants (Figure 3).

The data collected were processed in the Statistical Package for Social Sciences v. 20.0 (SPSS Inc., Chicago, IL, USA) software, then treated and analyzed using descriptive and inferential approaches, with a 5\% significance level. The Kolmogorov-Smirnov test was used to check whether the odontometric measurement data had a normal distribution. The Levene F test was used to verify the equal variances in the study variables. The other comparative analyses were performed using the Student's t test and repeated-measures analysis of variance (ANOVA) with Bonferroni.

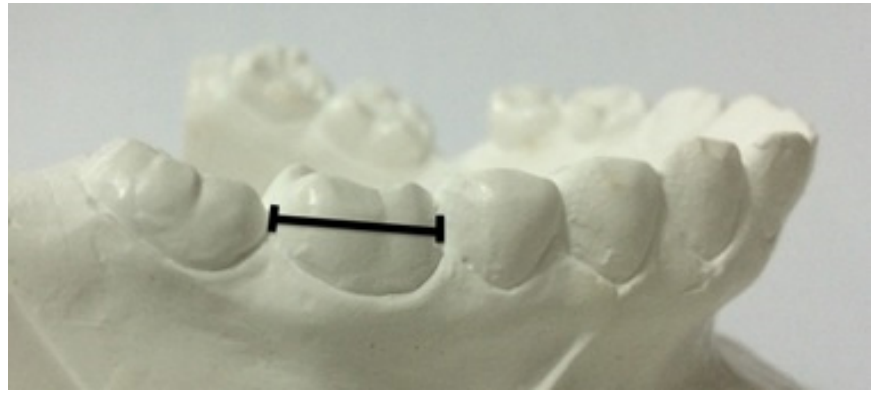

Fig.1. Mesiodistal distance. Source: current research.

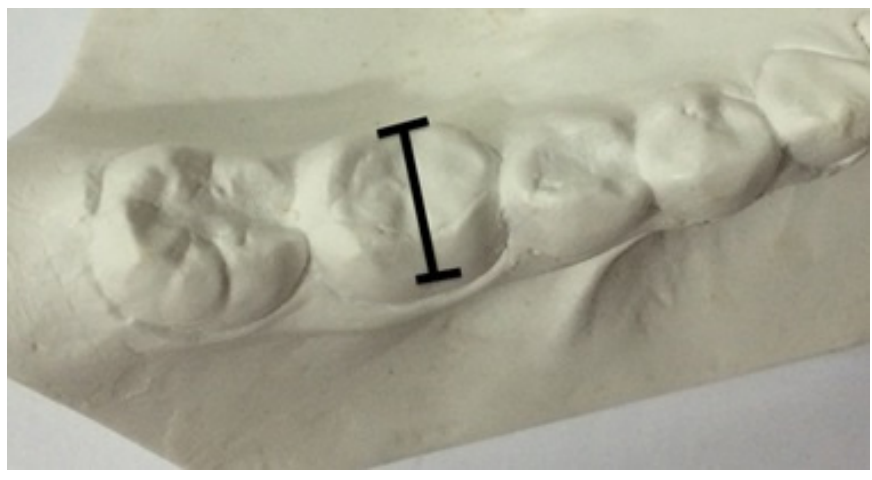

Fig.2. Buccolingual/Palatal distance. Source: current research.

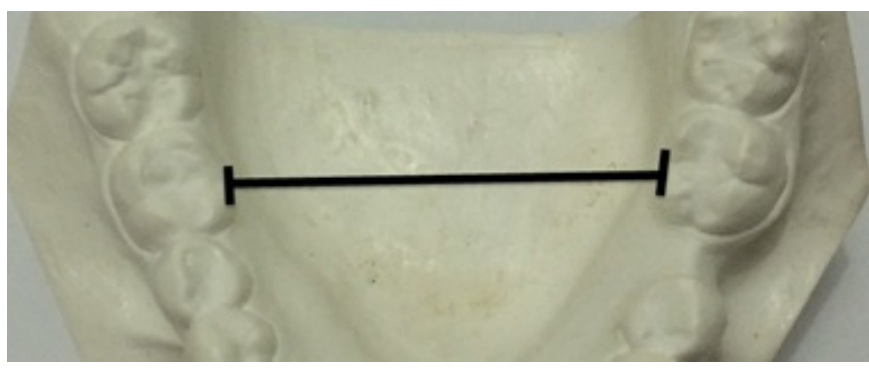

Fig.3. Distance between the lingual cusps of the molars in opposite quadrants. Source: current research.

\section{Results}

Table 1 describes the mean and standard deviation of the measurements according to tooth and sex. There was a significant difference between the MD and BL/BP widths in all first molars, and male teeth were found to be larger than the female ones $(p<0.05)$. As for second molars, only the maxillary and mandibular right second molars (\#17 and \#47, respectively) showed a statistically significant difference concerning their MD width $(p=0.034$ and $\mathrm{p}=0.044$, respectively). The mandibular left and right second molars (\#37 and \#47, respectively) showed a significant difference in their BL widths according to $\operatorname{sex}(p=0.007$ and $p=0.008$, respectively). Furthermore, there was a statistically significant sex differentiation in the segments from the maxillary right first molar (\#16) to the maxillary left first molar (\#26) $(\mathrm{p}=0.019)$; maxillary right second molar (\#17) to the maxillary left second molar (\#27) $(p=0.001)$; and the mandibular right second molar (\#37) to the mandibular left second molar $(\# 47)(\mathrm{p}=0.022)$. 
Table 1 - Mean and standard deviation of the measurements according to tooth and sex. Dental nomenclature follows the system proposed by the Federacion International Dental (FDI). João Pessoa, PB, Brazil, 2015.

\begin{tabular}{|c|c|c|c|c|c|c|}
\hline \multirow[b]{3}{*}{ Measures } & \multicolumn{5}{|c|}{ Sex } & \multirow[b]{3}{*}{ p-value ${ }^{1}$} \\
\hline & \multicolumn{3}{|c|}{ Male } & \multicolumn{2}{|c|}{ Female } & \\
\hline & Tooth & Mean & $\begin{array}{l}\text { Standard } \\
\text { deviation }\end{array}$ & Mean & $\begin{array}{l}\text { Standard } \\
\text { deviation }\end{array}$ & \\
\hline \multirow{4}{*}{ Mesiodistal } & 16 & $10.32^{a}$ & 0.57 & $9.84^{a}$ & 0.43 & $0.001^{*}$ \\
\hline & 26 & $10.26^{a}$ & 0.57 & $9.84^{a}$ & 0.50 & $0.008^{*}$ \\
\hline & 36 & $10.77^{\mathrm{b}, \mathrm{c}}$ & 0.67 & $10.25^{b}$ & 0.57 & $0.005^{*}$ \\
\hline & 46 & $10.66^{\mathrm{a}, \mathrm{c}}$ & 0.61 & $10.27^{\mathrm{b}}$ & 0.55 & $0.020^{*}$ \\
\hline$p$-value ${ }^{2}$ & & \multicolumn{2}{|c|}{$0.008^{*}$} & \multicolumn{2}{|c|}{$0.002^{*}$} & \\
\hline \multirow{4}{*}{$\begin{array}{l}\text { Buccolingual/ } \\
\text { Palatal }\end{array}$} & 16 & $10.48^{a}$ & 0.65 & $10.05^{a}$ & 0.46 & $0.010^{*}$ \\
\hline & 26 & $10.49^{a}$ & 0.55 & $10.09^{a}$ & 0.52 & $0.010^{*}$ \\
\hline & 36 & $10.14^{b}$ & 0.57 & $9.72^{b}$ & 0.46 & $0.006^{*}$ \\
\hline & 46 & $10.08^{b}$ & 0.63 & $9.64^{b}$ & 0.53 & $0.010^{*}$ \\
\hline p-value ${ }^{2}$ & & \multicolumn{2}{|c|}{$0.024^{*}$} & \multicolumn{2}{|c|}{$0.002^{*}$} & \\
\hline \multirow{4}{*}{ Mesiodistal } & 17 & 9.70 & 0.61 & $9.34^{\mathrm{a}}$ & 0.55 & $0.034^{*}$ \\
\hline & 27 & $9.59^{a}$ & 0.62 & $9.28^{a}$ & 0.57 & 0.066 \\
\hline & 37 & $10.34^{b}$ & 0.81 & $9.99^{b}$ & 0.54 & 0.075 \\
\hline & 47 & $10.26^{b}$ & 0.77 & $9.85^{b}$ & 0.65 & $0.044^{*}$ \\
\hline$p$-value ${ }^{2}$ & & \multicolumn{2}{|c|}{$<0.001^{*}$} & \multicolumn{2}{|c|}{$<0.001^{*}$} & \\
\hline \multirow{4}{*}{$\begin{array}{l}\text { Buccolingual/ } \\
\text { Palatal }\end{array}$} & 17 & $10.40^{a}$ & 0.77 & $10.07^{a}$ & 0.50 & 0.074 \\
\hline & 27 & $10.43^{a}$ & 0.78 & $10.08^{a}$ & 0.46 & 0.061 \\
\hline & 37 & $9.96^{b}$ & 0.59 & $9.51^{b}$ & 0.55 & $0.007^{*}$ \\
\hline & 47 & $9.82^{b}$ & 0.66 & $9.36^{\mathrm{b}}$ & 0.51 & $0.008^{*}$ \\
\hline p-value ${ }^{2}$ & & \multicolumn{2}{|c|}{0.004} & \multicolumn{2}{|c|}{$<0.001^{*}$} & \\
\hline \multirow{2}{*}{ Distances } & $16-26$ & 37.81 & 2.51 & 36.13 & 2.42 & $0.019^{*}$ \\
\hline & $36-46$ & 34.30 & 2.40 & 33.04 & 2.99 & 0.107 \\
\hline p-value ${ }^{2}$ & & \multicolumn{2}{|c|}{$<0.001^{*}$} & \multicolumn{2}{|c|}{$<0.001^{*}$} & \\
\hline \multirow{2}{*}{ Distances } & $17-27$ & 43.29 & 2.52 & 40.72 & 2.58 & $0.001^{*}$ \\
\hline & $37-47$ & 40.68 & 2.62 & 39.02 & 2.33 & $0.022^{*}$ \\
\hline p-value ${ }^{2}$ & & \multicolumn{2}{|c|}{$0.001^{*}$} & \multicolumn{2}{|c|}{$0.018^{*}$} & \\
\hline
\end{tabular}

*Statistically significant difference ( $p$-value<0.05).

${ }^{1}$ Student's $t$ test for equal variances.

${ }^{2}$ Repeated-measures ANOVA.

Obs: Different superscript letters indicate a statistically significant difference between the corresponding teeth according to Bonferroni's multiple (paired) comparisons test.

As described in Table 1, the mandibular left first molar (\#36) showed the highest MD width in males, statistically different from the other first molars. With regard to the other analyzed measurements, significant differences were observed both in first and second molars in opposite quadrants. For instance, mandibular teeth had higher MD width than maxillary teeth, while maxillary teeth had greater BL width. Similar findings were also observed in females, in which the measurements followed the same pattern of differences between maxillary and mandibular molars.

\section{Discussion}

University students attending public high education institutions, such as UFPB, commonly come from different ancestries and social classes. This fact has been accentuated by social inclusion policies (university quotas) gradually implemented in these institutions ${ }^{16}$.

Unlike bones, teeth are not much affected by nutritional deficiencies ${ }^{17}$. Hence, social factors and eating habits do not affect significantly determination of sex by the odontometric measurements of teeth. This fact places teeth as important auxiliary tools in the human identification process.

This study confirmed the existence of sex dimorphism based on odontometric measures of the maxillary/mandibular first and second permanent molars. Male teeth were found to be larger than the female ones and the distances between the lingual cusps of the corresponding molars in opposite quadrants were also higher in men. These results corroborate those found by studies assessing other populations ${ }^{12,18-22}$.

A limitation of this study lies in the inability to pinpoint a borderline numeric variation for the analyzed measures concerning the use of molar teeth for sex determination. This shortcoming may be explained by the small sample size, which may not have been sufficient to perform a discriminant statistical analysis, i.e., the comparison between sexes based on confidence intervals $(95 \%$ $\mathrm{CI})^{23}$. It is worth noting that one of the major difficulties in sample selection lied in the high frequency of ineligibility due to proximal restorations in the target teeth.

A study ${ }^{12}$ carried out in Greece investigated the degree of sex dimorphism in 344 permanent molars from 107 Greek (53 men and 54 women). The authors used the diameters of the crowns and the diagonal length of the cervical region as parameters for determination. They concluded that men have larger molars than women. Nevertheless, this Greek population was found to have their maxillary second molars as the most dimorphic teeth, which is in contrast with the findings presented here, as we found that maxillary first molars are unanimously larger in males.

In our study, the analysis of homologous teeth revealed that the mandibular first left and right molars (\#36 and \#46, respectively) in men showed a significant difference in their MD widths. A study performed in Peru ${ }^{24}$ investigated the relationship between the MD widths of teeth and sex. The authors used 120 plaster casts belonging to students ( 60 men and 60 women) aged 12 to 18 years. They found a significant discrepancy between the MD diameters of seven pairs of homologous teeth in men, including the mandibular first molars. They also observed an important relationship between the MD width and sex dimorphism, as men were found to have greater MD diameter than women.

Sex determination using dental parameters is employed in the process of forensic identification. Another study ${ }^{25}$ aimed to verify sexual dimorphism by $\mathrm{MD}$ and $\mathrm{BL} / \mathrm{BP}$ measurements. Two hundred plaster casts from Brazilian adults of both sexes, aged 20 to 30 years, were analyzed. The author concluded that male teeth are larger than female teeth, which corroborates the findings of our study. However, no significant differences were observed between homologous teeth, except for the MD width of the mandibular first right and left molars (\#36 and \#46, respectively). Furthermore, measuring of canines and molars was the best dental indicator to identify sex in this population, with the maxillary first molars showing sex distinction.

Sexual dimorphism based on tooth size varies among populations and even within the same population due to historical and evolutionary reasons. Accordingly, the criteria set down in one place may not apply to another, requiring determination of specific values for each population ${ }^{17}$. It is Important to consider that the Brazilian population is composed by miscegenation of different 
ethnic groups, which influences and hinders the identification of sex based on odontometric analysis. Even so, when odontometry is employed with this purpose, the most commonly used dimensions are the MD and BL distances ${ }^{1,7,20,26-29}$.

Participation of dentists in the forensic staff is beneficial to the victim and their family ${ }^{30}$. An expert analysis of the stomatognathic system, especially the teeth, is able to guide criminal investigations, in which the inclusion of forensic dentists is a unanimous requirement in accredited institutes.

Forensic dentistry is an area of great importance in the forensic practice and is a useful tool in the studies related to human identification methods, in particular the use of teeth. The results observed in this study led us to conclude that the maxillary first molars were found to have the highest percentage of sex dimorphism and that male molars are larger than those of the opposite sex.

\section{Acknowledgements}

The authors are thankful to the National Council for Scientific and Technological Development for financial support.

\section{References}

1. Niquini BTB, Villalobos MIOB, Manzi FR, Bouchardet FCH. [Need of an estimation method by teeth in civil law - case report]. Rev Bras Odontol Legal. 2015;2(2):116-25.[Portuguese.

2. VermaAK, Kumar S, Rathore S, PandeyA. Role of dental expert in forensic odontology. Natl J Maxillofac Surg. 2014 Jan;5(1):2-5. doi: 10.4103/09755950.140147.

3. Frari P, Iwashita ARFG, Caldas JC, Scanavin MA, Daruge Junior E. [The importance of forensic dentistry in human identification processes of mass disaster victims. Suggestion of forensic exam protocol]. Rev Odonto. 2008 Jan-Jun;16(31):38-44. Portuguese.

4. Araújo LG, Biancalana RC, Terada ASSD, Paranhos LR, Machado CEP, Silva RHA. [Human identification of victims of mass disasters: the importance and role of Forensic Dentistry]. RFO UPF. 2013 MayAug;18(2):224-9. Portuguese.

5. Blakaj F, Bicaj T, Bicaj B. Dental identification of a decomposed body. Med Arh. 2010;64(2):125-6.

6. Terada ASSD, Leite NLP, Silveira TCP, Secchieri JM, Guimarães MA, Silva RHA. Human identification in forensic dentistry from a photographic record of smile: a case report. Rev Odontol UNESP. 2011 Jul-Aug;40(4):199-202.

7. Kapila R, Nagesh KS, R lyengar A, Mehkri S. Sexual dimorphism in human mandibular canines: a radiomorphometric study in South Indian population. J Dent Res Dent Clin Dent Prospects. 2011 Spring;5(2):51-4.

8. Acharya AB, Prabhu S, Muddapur MV. Odontometric sex assessment from logistic regression analysis. Int J Legal Med. 2011 Mar;125(2):199-204. doi: 10.1007/s00414-010-0417-9.

9. Costa YTF, Lima LNC, Rabello PM. Analysis of canine dimorphism in the estimation of sex. Braz J Oral Sci. 2012 Jul-Sep;11(3):406-10.

10. Belotti L, Rabbi R, Pereira SDR, Barbosa RS, Carvalho KS, Pacheco KTS. [Is it possible to identify positively a charred body using only two teeth? A forensic case report]. Rev Bras Odontol Legal. 2015;2(2):105-115. Portuguese.
11. Macaluso PJ Jr. Sex discrimination potential of permanent maxillary molar cusp diameters. J Forensic Odontostomatol. 2010 Dec 1;28(1):22-31.

12. Zorba E, Moraitis K, Manolis SK. Sexual dimorphism in permanent teeth of modern Greeks. Forensic Sci Int. 2011 Jul 15;210(1-3):74-81. doi: 10.1016/j.forsciint.2011.02.001.

13. França GV. Legal Medicine. Rio de Janeiro: Guanabara Koogan; 2015 Portuguese.

14. Khangura RK, Sircar K, Singh S, Rastogi V. Sex determination using mesiodistal dimension of permanent maxillary incisors and canines. $J$ Forensic Dent Sci. 2011;3(2):81-85.

15. Vanrell J. [Forensic Dentistry and Forensic Anthropology]. Rio de Janeiro: Guanabara Koogan; 2009. Portuguese.

16. Naiff DGM, Naiff LAM, Souza MA. College students social representations on racial quotas in public universities in Brazil. Estud. Pesqui. Psicol. 2009;9(1):216-29.

17. Barros AIM. [Association study between nutrition status and oral health in 6 to 12 years old children / adolescents of a school community] [thesis]. Porto: The Faculty of Nutrition and Food Sciences of the University of Porto; 2010. Portuguese.

18. Galdames JCS, Matamala DAZ, Smith RL. Blind test of mandibular morphology with sex indicator in subadult mandibles. Int J Morphol. 2008;26(4):845-8.

19. Hattab FN, Al-Khateeb S, Sultan I. Mesiodistal crown diameters of permanent teeth in Jordanians. Arch Oral Biol. 1996;41(7):641-5.

20. Lund $H$, Mörnstad H. Gender determination by odontometrics in a Swedish population. J Forensic Odontostomatol. 1999;17(2):30-4.

21. Khangura RK, Sircar K, Singh S, Rastogi V. Sex determination using mesiodistal dimension of permanent maxillary incisors and canines. $J$ Forensic Dent Sci. 2011;3(2):81-5.

22. Shankar S, Anuthama K, Kruthika M, Kumar VS, Ramesh K, Jaheerdeen $A$, et al. Identifying sexual dimorphism in a paediatric South Indian population using stepwise discriminant function analysis. J Forensic Leg Med. 2013;20(6):752-6.

23. Vieira S. Bioestatistics: advanced topics. Rio de Janeiro: Elsevier; 2010. Portuguese.

24. León GJC, Vargas LFP, Tamariz MAC, Luque HJL. [Comparative study of the mesio-distal size between homologous teeth in permanent dentition]. Odontol. Sanmarquina. 2013;16(2):7-11. Spanish.

25. Martins Filho IE. [Relationship between gender and tooth measures: a Brazilian study] [thesis]. São Paulo: University of São Paulo, the São Paulo School of Dentistry; 2013. Portuguese.

26. Ates M, Karaman F, Iscan MY, Erdem TL. Sexual differences in Turkish dentition. Leg Med (Tokyo). 2006 Oct;8(5):288-92.

27. Angadi PV, Hemani S, Prabhu S, Acharya AB. Analyses of odontometric sexual dimorphism and sex assessment accuracy on a large sample. J Forensic Leg Med. 2013 Aug;20(6):673-7. doi: 10.1016/j. jflm.2013.03.040.

28. Khan SH, Hassan GS, Rafique T, Hasan N, Russell SH. Mesiodistal crown dimensions of permanent teeth in Bangladeshi population. BSMMU J. 2011;4(2):81-7.

29. Pereira C. [Forensic dental medicine]. Lisboa: Lidel; 2012.

30. Ribas-e-Silva V, Terada ASSD, Silva RHA. [The importance of the dentist's specialized knowledge into Brazilian forensic team]. Rev Bras Odontol Legal. 2015;2(1):68-90. Portuguese. 